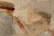

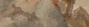

Fis.

Mos:

(1)

ars $\rightarrow$

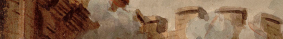

WDithe te is
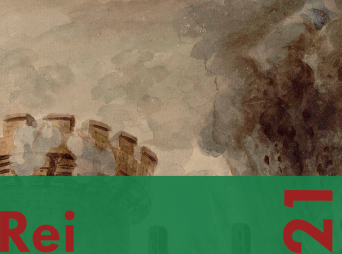

Revista digital de Historia

y Didáctica de la Historia 
Revista anual

Fecha de inicio: 1995

RevistaPantaRei.pantarei@um.es

\section{Edita:}

Centro de Estudios del Próximo Oriente y la

Antigüedad Tardía - CEPOAT

Edificio Universitario Saavedra Fajardo.

Universidad de Murcia

C/ Actor Isidoro Máiquez, 9

30007 - MURCIA - ESPAÑA

Teléfono: $(+34) 868883890$

cepoat@um.es

Web: https://revistas.um.es/pantarei

\section{Ediciones de la Universidad de Murcia - EDITUM}

Edificio Pleiades. Campus de Espinardo.

Universidad de Murcia

C/ Campus, s/n

30100 - MURCIA - ESPAÑA

Teléfono: (+34) 868883013

editum@um.es

Web: https://www.um.es/web/editum/

En portada: Prise de la Bastille. Biblioteca Nacional de Francia (BNF).

Edición 2021

ISSNe: 2386-8864

ISSN: $1136-2464$

Depósito legal: MU-966-1995

Responsables de los textos: sus autores.

Responsable de la presente edición: Consejo Editorial de Panta Rei. 


\section{CONSEJO DE REDACCIÓN}

Coordinador editorial

Egea Vivancos, Alejandro [Didáctica de la Historia, Universidad de Murcia]

Secretaria

Arias Ferrer, Laura [Didáctica de la Historia, Universidad de Murcia]

Editores

Bellatti, Ilaria [Didáctica de la Historia, Universidad de Barcelona]

Jiménez Vialás, Helena [Historia Antigua, Universidad de Murcia]

Martínez Gil, Tània [Didáctica de Historia,

Universidad de Barcelona]

Meseguer Gil, Antonio José [Historiador, Profesor de Secundaria]

Ortiz García, Jónatan [Arqueología, Universidad de Alcalá de Henares]

Romero Molero, Alberto [Arqueología, Universidad Isabel I]

Sáez Giménez, David Omar [Historiador, Profesor de Secundaria]

Sáez Rosenkranz, Isidora V. [Didáctica de la Historia, Universidad de Barcelona]

Sánchez Mondejar, Celso Miguel [Arqueólogo,

Patrimonio Inteligente]

Responsables de traducción y corrección lingüística

Martínez Martínez, Cristina [Profesora de Secundaria, Sociedad Española de Lenguas Modernas] Albaladejo Albaladejo, Sara [ISEN-Universidad de Murcia]

\section{CONSEJO ASESOR}

Adroher Auroux, Andrés María [Arqueología, Universidad de Granada]

Albero Muñoz, $M^{a}$ del Mar $\left[H{ }^{a}\right.$ del Arte, Universidad de Murcia]

Alia Miranda, Francisco [Historia Contemporánea, UCLM]

Arciniega García, Luis [Historia del Arte, Universidad de Valencia]

Barrio Barrio, Juan Antonio [Historia Medieval,

Universidad de Alicante]

Castellano i Solé, Núria [Egiptología, Schola

Didàctica Activa S.L.]

Chapman, Arthur [History Education, University

College of London, Reino Unido]

Chavarria Arnau, Alejandra [Arqueología, Università di Padova, Italia]

Cid López, Rosa María [Historia Antigua, Universidad de Oviedo]

Cobacho López, Ángel [Derecho, Universidad de Murcia]

Cuenca López, José María [Didáctica de la Historia, Universidad de Huelva]

Egea Bruno, Pedro M. ${ }^{a}$ [Historia Contemporánea, Universidad de Murcia]
Feijoo Martínez, Santiago [Arqueología, Consorcio

Ciudad Monumental de Mérida]

García Atienzar, Gabriel [Prehistoria, Universidad de

Alicante]

Ginestí Rosell, Anna [Filología Clásica, Katholische

Universität Eichstätt-Ingolstadt]

González Monfort, Neus [Didáctica de la

Historia, Universidad Autónoma de Barcelona]

González Soutelo, Silvia [Arqueología, Universidad

Autónoma de Madrid]

Haber Uriarte, María [Prehistoria, Universidad de

Murcia]

Hernández de la Fuente, David [Filología Clásica,

Universidad Complutense]

Hutson, Scott R. [Anthropology, University of Kentucky, EEUU]

lgual Luis, David [Historia Medieval, UCLM]

Irigoyen López, Antonio [Historia Moderna,

Universidad de Murcia]

Jover Maestre, Francisco Javier [Prehistoria,

Universidad de Alicante]

Mahony, Simon [Digital Humanities, University College

of London, Reino Unido]

Marsilla de Pascual, Francisco Reyes [Técnicas

historiográficas, Universidad de Murcia]

Martínez-Burgos García, Palma [H. ${ }^{a}$ del Arte, UCLM]

Mathis, Christian [Didaktik der Geschichte, PH Zürich]

Miralles Maldonado, José Carlos [Filología Clásica,

Universidad de Murcia]

Molina Gómez, José Antonio [Historia Antigua,

Universidad de Murcia]

Mónica Ghirardi [Historia Moderna, Universidad

Nacional de Córdoba, Argentina]

Navarro Espinach, Germán [Historia Medieval,

Universidad de Zaragoza]

Ni Cassaithe, Caitriona [Didáctica de la Historia,

Dublin City University, Irlanda]

Noguera Celdrán, José Miguel [Arqueología,

Universidad de Murcia]

Ortiz Heras, Manuel [Historia Contemporánea, UCLM]

Panzram, Sabine [Historia Antigua, Universität

Hamburg]

Pérez Molina, Miquel Emilio [Filología Clásica,

Universidad de Murcia]

Pinto, Helena [Didáctica de la Historia, CITCEM

University of Porto, Portugal]

Prados Martínez, Fernando [Arqueología,

Universidad de Alicante]

Sánchez lbáñez, Raquel [Didáctica de la Historia, Universidad de Murcia]

Sancho Gómez, Miguel Pablo [Educación, UCAM]

Victoria Moreno, Diego [Historia Contemporánea, UNED]

Vilar García, María José [Historia Contemporánea,

Universidad de Murcia]

Vivas Sainz, Inmaculada [H. ${ }^{a}$ del Arte, UNED]

Zamora López, José Ángel [Próximo Oriente Antiguo, CCHS-CSIC] 



\section{Índice}

\section{Artículos}

Libelos, camarillas y banquetes: una propuesta para reconstruir las proclamaciones militares en la 7 Antigüedad Tardía a través de los casos de Probo, Magnencio y Juliano

Miguel Pablo Sancho Gómez

El uso de los videojuegos para la enseñanza de la Historia Antigua en Educación Secundaria: una investigación educativa

Manuel Jesús Jaldón-Méndez Sánchez

'What did it achieve?' - Students' conceptions about the significance of the French Revolution

Christian Mathis

Pervivencia e influencia de los mitos fundacionales del franquismo en los textos escolares de la enseñanza secundaria castellanoleonesa

Sergio Ibáñez Llorente y Almudena Alonso-Centeno

La enseñanza y aprendizaje de las Ciencias Sociales a través del patrimonio, videojuegos y emociones. 103 Estudio de caso en un IES de Huelva (España)

Rocío Jiménez-Palacios y José María Cuenca López

Desarrollo de la conciencia histórica. Una propuesta de intervención y evaluación para la Educación de Adultos

Héctor López-Bajo, Rosendo Martínez Rodríguez y María Sánchez-Agustí

Concepciones de docentes en formación suecos y españoles sobre la desigualdad de género en perspectiva temporal

Jorge Ortuño Molina y Fredrik Alvén

Narrativa y significación histórica en la comunicación de los museos nacionales canadienses en Facebook

Iñaki Navarro-Neri, Pilar Rivero, Borja Aso y Ana Mendioroz-Lacambra

\section{Entrevista}

Haciendo historia para el bien común. Entrevista a Linda S. Levstik

Laura Arias Ferrer y Alejandro Egea Vivancos

\section{Reseñas}

M. Sartre (2021), Le Bateau de Palmyre. Quand les mondes anciens se rencontraient (Vle siècle av. J.- 239

C./Vle siècle ap. J.-C.), Paris: Éditions Tallandier

Juan Álvarez García

Janire Castrillo, Las mujeres vascas durante la Baja Edad Media. Vida familiar, capacidades jurídicas, 245 roles sociales y trabajo, Madrid, Sílex Universidad, 2020

Iratxe Gillate

M. Ortiz Heras (coord.). (Manual de) Historia de España (siglo XX). Del desastre del 98 a la crisis 249 sistémica actual, Albacete: Altabán, 418 págs. ISBN: 978-84-15252-46-7

Herminio Lebrero Izquierdo 



\title{
Libelos, camarillas y banquetes: una propuesta para reconstruir las proclamaciones militares en la Antigüedad Tardía a través de los casos de Probo, Magnencio y Juliano
}

\author{
Libels, cabals and feasts: a proposal to reconstruct military \\ proclamations in Late Antiquity through the cases of Probus, Magnentius \\ and Julian
}

\author{
Miguel Pablo Sancho Gómez \\ Universidad Católica de Murcia \\ mpsancho@ucam.edu \\ 0000-0003-0528-1721
}

Recibido: 12/05/2021

Aceptado: 29/07/2021

\begin{abstract}
Resumen
Pese a la gran cantidad de sublevaciones militares acontecidas en el Imperio Romano, y muy especialmente en el siglo III, sabemos muy poco de cómo se preparaban y ejecutaban sobre el papel estos complots. Quitando el atípico caso de Procopio, relatado con detalle por Amiano Marcelino, las fuentes literarias, ya en muchos casos problemáticas $\mathrm{y} / 0$ escasas, dejan bastantes lagunas en los relatos de tales procesos, que la historiografía reciente intenta suplir con hipótesis. Sin entrar a valorar las motivaciones del fenómeno o el grado de responsabilidad de los diferentes involucrados en las denominadas usurpaciones, nos planteamos ofrecer una propuesta explicativa desde el punto de vista meramente técnico, esto es, cómo un determinado grupo de conjurados logra idear, planear y ejecutar un plan $\circ$ una serie de planes con el objetivo de alcanzar el poder mediante el apoyo de ciertas fuerzas militares para derrocar, casi siempre asesinando, al emperador reinante.
\end{abstract}

\section{Palabras clave}

Historia, Historia Antigua, Arte de la guerra, Fuerzas armadas, Antigüedad.

\begin{abstract}
Despite the large number of military uprisings that occurred in the Roman Empire, and especially in the Third Century, we know very little about how these conspiracies were prepared and executed on paper. Not counting the atypical case of Procopius, related in detail by Ammianus Marcellinus, the literary sources, already problematic and /or scarce in many cases, leave many gaps in the accounts of such processes, which recent historiography tries to fill with hypotheses. Without assessing the motivations of the phenomenon or the degree of responsibility of the different parties involved in the so-called usurpations, we offer an explanatory proposal from the merely technical point of view, that is, how a certain group of conspirators manages to devise, scheme and execute a plan or series of plans with the aim of attaining power through the support of certain military forces and overthrow, almost always assassinating, the reigning emperor.
\end{abstract}

\section{Keywords}

History, Ancient History, Warfare, Army, Antiquity.

Para citar este artículo: Sancho Gómez, M. P. (2021). Libelos, camarillas y banquetes: una propuesta para reconstruir las proclamaciones militares en la Antigüedad Tardía a través de los casos de Probo, Magnencio y Juliano. Panta Rei: revista digital de Historia y didáctica de la Historia, 7-29. doi: $10.6018 /$ pantarei.475981 


\section{Introducción}

El siglo III de nuestra era contempló un incremento pronunciado en las rebeliones procedentes del ejército, especialmente en comparación con la época imperial anterior. Si bien es cierto que algunos de los primeros príncipes, como Nerón, se vieron afectados por este fenómeno, el descontento o la agitación en los resortes del poder estatal no llegó al despliegue pleno y a gran escala de violencia mediante el desencadenamiento de auténticas guerras civiles a lo largo y ancho del Imperio, con confrontaciones y batallas en las provincias y enfrentamientos masivos de ejércitos formados por varias legiones. Las excepciones, aunque destructivas y decisivas por su notable impacto, se reducen a dos: la guerra del año 69, de la que emergieron los Flavios (Morgan, 2007), y el conflicto que de 193 a 197 sacudió las estructuras imperiales hasta sus cimientos para terminar con la instauración de los Severos (Christol, 1007; Potter, 2004).

En cambio, durante una parte muy importante del siglo III, la aparición de usurpadores fue la norma. La situación alcanzó su cénit en el reinado de Galieno en solitario (259/260-268), que además llegó a ver el Imperio escindido en tres estados paralelos. El fenómeno decrece sensiblemente, aunque no desaparece, con Aureliano y Probo, para alcanzar una etapa de estabilidad duradera, aunque no definitiva, con Diocleciano (284-305), que tuvo que lidiar con la última de las secesiones del periodo, la del Imperio Britano, entre 286 y 297 (Casey, 1995; Omissi, 2018). Por todo ello, se puede afirmar que desde 235 hasta 285 los momentos de calma resultaron la excepción en una época convulsa. Aunque ciertas áreas del Imperio se vieron mucho menos afectadas que otras durante la denominada "Anarquía Militar", por obvios motivos geopolíticos, la proliferación de rebeliones militares está fuera de toda duda (Alföldy, 1974; Birley, 1976; Fernández Ubiña, 1982; Hartmann, 2017; Omissi, 2018; Walser, 1965).

Trataremos de mostrar el desarrollo de estas maquinaciones, golpes, y/o revueltas ofreciendo un esquema general en base a los testimonios de las fuentes literarias. Existen algunos elementos de carácter técnico comunes, y creemos que imprescindibles, para gestar estas rebeliones, que propiciaron la aparición de un usurpador con apoyo militar. Al tratarse de fenómenos reveladores de la tensión reinante desde los puntos de vista político y social en vastas áreas del Imperio Romano, consideramos importante su análisis como elementos sintomáticos de desafío al poder establecido. En el presente estudio procederemos a diseccionar el proceso por el cual se fraguaban las usurpaciones, mediante el uso del método comparativo y el análisis textual, pues creemos que de tal modo es posible desentrañar el aspecto técnico subyacente en tales fenómenos.

\section{Las fuentes literarias: teoría y estudio de su contexto}

Antes de empezar, aclararemos algunos conceptos necesarios. Técnica viene del griego tékne o

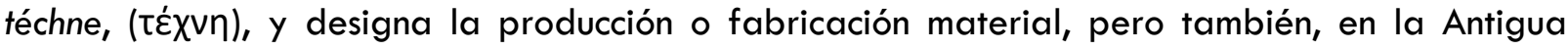
Grecia, la acción eficaz. El término ha seguido siendo estudiado recientemente (Montoya Suárez, 2008). La séptima acepción de "técnica" en el diccionario de la RAE es "habilidad para ejecutar cualquier cosa, o para conseguir algo"l.

\footnotetext{
1 https://dle.rae.es/t\%C3\%A9cnico\#ZlkyMDs consultado el 22 de marzo de 2021.
} 
En ese sentido, nuestro estudio intentará describir y mostrar la acción o acciones técnicas por la(s) que se generaban las rebeliones características del Imperio tardío denominadas usurpaciones. Nos apoyaremos en el modelo histórico reseñado por Saenz-Rosenkranz (2016) a la hora de definir las diferentes partes del presente trabajo, y más concretamente nos centraremos en el método comparativo.

Cabe destacar la importancia capital de las fuentes literarias en las investigaciones de Historia Antigua, pues, aunque puedan complementarse notablemente con los frutos de la arqueología, epigrafía, numismática y otras ciencias de gran valor, siguen configurando la base sobre la que se asienta la parte más importante de los estudios científicos contemporáneos, y sobre ellas recaerá aquí el principal peso de la importante fase de análisis e interpretación (Cardoso, 2000).

A continuación, se describirá el carácter, morfología y particularidades principales de las fuentes literarias a estudiar mediante comparación textual, y posteriormente se expondrán las tres ascensiones al poder desde la rebelión (Probo, Magnencio, Juliano), ya que en esos casos concretos se han conservado datos suficientes para valorar el proceso estudiado en el actual trabajo, esto es, la vertiente técnica de un levantamiento o sublevación, que implica a una parte del ejército y/o funcionariado imperial para hacerse con el poder, derrocando, y casi siempre eliminando, al emperador reinante. Tales sucesos, como se ha dicho, constituyen una característica de magnitud en el Imperio tardío, y nuestro objetivo es estudiar dicha faceta técnica mediante la comparación en las fuentes literarias, pues creemos poder reconstruir el proceso a través de los casos presentados.

\subsection{La Historia Augusta}

La Historia Augusta es una de las fuentes más controvertidas de la Antigüedad Tardía; la historiografía contemporánea especializada se ha ocupado a fondo de sus muchos interrogantes en las últimas décadas. Gran cantidad de investigadores han tratado de desvelar el misterio, sin éxito: pese a los ríos de tinta vertidos y las numerosas conjeturas, tanto fundadas como infundadas, la obra continúa siendo un campo plagado de incógnitas. Pero no obstante se ha podido añadir cierta luz adicional gracias a la segunda información del texto, su estilo, gustos y opiniones. También es reseñable una audacia literaria que va in crescendo conforme avanza la obra, y que a veces traiciona parcialmente los deseos de secretismo que obviamente primaron al escribirla (Velaza, 2017).

Gran cantidad de características anormales diferencian este producto del resto de obras de su tiempo. Pretendidamente, estamos ante biografías imperiales confeccionadas por seis autores distintos: pero hay mucho más. Las fabricaciones, los anacronismos, los gustos de gramático, el vocabulario, etc. señalan un momento histórico muy posterior a Constantino o Diocleciano, que reciben dedicatorias extremadamente sospechosas en varias secciones, lo que puso por primera vez en alerta a la historiografía contemporánea, que retrasó notablemente la fecha de creación (Dessau, 1889). Se adora a los buenos emperadores, y hay un anhelo visible por la gloria perdida de Roma. Se observa el gusto por la cultura y el senado, pero ante el éxito militar de los Emperadores llirios o los Tetrarcas, se muestra entusiasmo; la Historia Augusta crea "restauraciones senatoriales", o presenta a un emperador como amante del senado, siempre que derrotase a los bárbaros. 
H. Dessau también puso en tela de juicio la autoría múltiple, y los nombres de esos seis Scritptores Historiae Augustae que a día de hoy se reconocen universalmente como ficticios. La característica literaria principal es con mucho esa predilección por el fraude, las invenciones, las falsificaciones y los engaños más variados; no en vano, R. Syme acuñó la expresión de "rogue scholar" para referirse al desconocido escritor (Syme 1983, p. 62). Otro de los factores que desde siempre ha llamado la atención de la investigación es la extrañísima abundancia de nombres inventados para presuntos escritores, poetas, historiadores, etc. Algunos de ellos ya pusieron bajo sospecha a Hermann Dessau, por su carácter claramente intempestivo. El motivo para empezar a redactar la Historia Augusta es otro misterio, especialmente si tenemos en cuenta que se ha perdido el prólogo de la obra (Sancho Gómez, 2018).

El entorno social y cultural mostrado nos lleva a la literatura común generada en su tiempo. El autor parece erudito, es libresco y quizás esté relacionado con la enseñanza, las bibliotecas, o el bajo funcionariado imperial. En cualquier caso, se muestra cercano a los escoliastas. Es también antimilitarista, y contrario a la autocracia. Hay burlas, en ocasiones, de las pretensiones genealógicas de la nobleza, pese al ya mencionado respeto, incluso admiración devota, por el senado romano.

Puede observarse un poderoso sentimiento de aprecio por la simbólica ciudad de Roma. El autor conocía bien la Urbs y estaba familiarizado con sus lugares más emblemáticos: la sensación percibida es que la Historia Augusta está escrita por alguien originario de Roma, o que ha vivido en ella mucho tiempo. Esta tendencia va unida a una cierta animadversión contra las capitales imperiales de su tiempo, que habían acaparado la primacía política, y contra la nueva religión, el cristianismo, retratado siempre con fría ironía, o de forma maliciosa, aunque no exenta de curiosidad (Sancho Gómez, 2016; 2018).

Pese a todo ello, sabemos que en estas biografías se emplearon como fuentes una notable cantidad de autores, algunos de ellos de calidad, perdidos y desconocidos para nosotros hoy, pero que añaden una cantidad importante de información valiosa y verdadera que, no obstante, ha de desbrozarse a través de un proceso de escrutinio y crítica a veces agotador y desmoralizante. Pero para nosotros uno de esos casos resulta de la mayor importancia. Las fuentes sobre Marco Aurelio Probo (276-282) son escuetas, con la excepción de la encomiástica y panegírica biografía presente en una obra, como ya hemos dicho, llena de problemas, y en muchas ocasiones carente de crédito, como es la Historia Augusta. No obstante, algunos retazos y pinceladas de información auténtica florecen en ese texto desde las mencionadas fuentes perdidas, que se manejaron en esos tiempos de epitomadores y autores redescubiertos. El estudio de esas obras detectadas y rastreadas, como la Kaisergechichte y su consiguiente problemática textual, datan de los tiempos de la Quellenforschung (Enmann, 1884). Aunque la cautela, e incluso la desconfianza, son muy necesarias, por no decir ineludibles y obligatorias, creemos que, en lo que se refiere al emperador Probo, aparecen detalles dignos del mayor interés, como veremos más adelante.

\subsection{Amiano Marcelino}

Sin lugar a dudas, Amiano es el historiador más importante del siglo IV. Nacido en Antioquía, probablemente en 330, y muerto poco después del año 400, este historiador, que se define a sí mismo como militar y griego (miles et graecus; Amm. Marc. XXXI 16, 9.), sirvió como oficial de 
Estado Mayor en el ejército romano. Retirado del servicio activo en 363, tras la fracasada expedición persa de Juliano, en la que tomó parte, regresó a su ciudad natal y comenzó a trabajar en la idea de una Res Gestae, en la que poder reunir los hechos más memorables desde el emperador Nerva (96-98) hasta su época, aunque por desgracia se han perdido los primeros trece libros, que llegaban al año 353. Adornada por ciertos pasajes descriptivos y las premisas retóricas de vigor en la época, la narración de Amiano Marcelino es no obstante una sólida historia llena de ponderación, aunque no siempre de objetividad; pese a ello, ha sido considerado en ocasiones como un fiel heredero de Tucídides (Matthews, 1989). Aparte de su reconocida admiración por Juliano, y la encendida defensa del general Ursicino, a cuyo estado mayor perteneció durante años, se puede apreciar una gran sobriedad de ejecución y un análisis agudo y pormenorizado, en el que se deja ver a menudo su espíritu militar. Una gran parte de nuestra información disponible sobre Juliano y Constancio II, Valente, Graciano y Valentiniano I, procede del extenso relato de Amiano. Además, resulta especialmente importante para los casi cinco años de reinado de Juliano como César en Occidente. Amiano fue testigo, e incluso protagonista, de algunos de los hechos que narra, y en otros casos sabemos que pudo informarse mediante archivos, documentos oficiales o entrevistas, que le proporcionaron no pocos datos confidenciales (Woods, 1998). Esta última peculiaridad nos resulta de enorme interés con vistas a analizar los sucesos iniciados en París que llevaron al poder supremo a Juliano. Aunque el texto no plantea los problemas de la Historia Augusta, también se impone un análisis sobrio, teniendo en cuenta la admiración ya citada del historiador por el personaje. No obstante, hemos de señalar que pese a alabar muchas características del gobierno y la personalidad de Juliano, Amiano tampoco se priva de criticar cuestiones que le resultan inaceptables o equivocadas (Sancho Gómez, 2011; Sidwell, 2008).

Amiano, como hemos indicado en el resumen de este trabajo, relató pormenorizadamente una usurpación, la de Procopio, perteneciente a la familia de Juliano, en los años 365-366 (Mleczek, 2015; Tomlin, 1979). Es curioso comprobar que, en tal episodio, pese a contar con auspicios favorables y ciertos apoyos militares y sociales, el principal interesado desaprovecha toda la ventaja: estando el emperador legítimo (Valente) pensando seriamente en la huida, la narración amianea se convierte en un retrato de tintes ominosos que refleja la gran decepción de una intentona titubeante; la flaqueza de ánimo aparece como el principal defecto de un Procopio que no supo aprovechar sus oportunidades y que, con timidez primero, y torpeza después, restituyó la confianza a un Valente casi desesperado. El sofocamiento de la fracasada rebelión y la ejecución del pretendiente ofrecen un cuadro aciago que contrasta fuertemente, dentro de su relato, con la actitud arrojada que había mostrado anteriormente Juliano a la hora de hacerse con el poder supremo en la Galia, y que trataremos con detalle a continuación.

\subsection{Libanio}

Imprescindible para comprender el Imperio de Oriente en su totalidad durante el siglo IV, Libanio (314-393/404) se erigirá como una figura peculiar y polémica que gravitará sobre el devenir de su ciudad natal, Antioquía, durante toda su prolongada vida. Nacido de una familia perteneciente a la aristocracia urbana, siempre se enorgullecerá de la riqueza y el poder de sus antepasados, una situación que menguará dramáticamente en su tiempo, ya que con su fallecimiento aconteció el final de su estirpe (López Eire, 1996). 
Libanio dedicó todos sus esfuerzos, ya desde su primera adolescencia, a estudiar para convertirse en un sofista (rétor). Apasionado y combativo defensor del helenismo, escribió su obra en un griego elevado y purista. Se sintió ufano de su desconocimiento total del latín, en el que se encontraba inherente un velado desprecio hacia Roma y su dominio universal. Para él lo único verdaderamente digno de admiración era la cultura griega, y en especial, el arte de la retórica. Huérfano de padre desde muy joven, su madre y su tío Fasganio se esforzaron al máximo para que recibiese la mejor educación posible. Alrededor de 355 comenzará una formal y cortés relación epistolar con el recién nombrado César Juliano, un joven amante de las letras en el que sin duda Libanio puso sus ojos como posible salvador del helenismo desfalleciente. Pero la amistad en ese momento no fue a más. Tras la triunfante coronación de Juliano como Augusto único, la situación cambiará drásticamente, máxime cuando el emperador se dirigió a Antioquía para organizar su campaña contra los persas. Tras un primer encuentro agradable y cariñoso, la relación entre ambos se fue enturbiando hasta el punto de producirse un grave distanciamiento, dada la suspicacia terrible de Libanio y la gran sensibilidad de Juliano; sus peculiaridades estuvieron a punto de provocar un desencuentro, que se evitó gracias a la mediación del filósofo Prisco, amigo de ambos. Parece que desde ese momento la situación mejoró, y que se despidieron como buenos amigos, tras convivir diariamente durante los últimos tiempos de estancia del emperador en la ciudad. A la vez, la relación entre Juliano y los habitantes de Antioquía, llena de malentendidos desde el principio, llegó a un punto de rechazo mutuo tal que Libanio se vio obligado a mediar entre sus conciudadanos y el Augusto. Pero la parte más sincera y valiente de esta amistad llegaría después de la muerte de Juliano, cuando Libanio, pese a un clima de creciente persecución, se convirtió en un gallardo y fiel defensor de la memoria de su amigo, en un tiempo en el que podía haberle acarreado desastrosas consecuencias (Sancho Gómez, 2011).

De su gigantesco corpus de 1554 cartas conservadas, puede apreciarse perfectamente el extremo cuidado puesto por Libanio en su correspondencia y sus extensas relaciones sociales; hay que tener en cuenta que a buen seguro la colección no nos ha llegado al completo. También se conservan decenas de oraciones (discursos), declamaciones y otras obras de retórica, en las que muchas veces aparecen asuntos de gran trascendencia para la época y que nos ofrecen valiosa información, aunque desde su punto de vista, ciertamente interesado. Por ello, Libanio se trata de una figura vital para cualquier estudio global del Imperio Tardío, y para nosotros con más razón, dada la íntima amistad que mantuvo con Juliano. "Maestro" igualmente del emperador, en su Discurso fúnebre sobre Juliano vuelve sobre los hechos de la proclamación en París que vamos a analizar después, desde una visión íntima, a veces conmovedora, pero en definitiva favorable y partidista.

\subsection{Eutropio y Aurelio Víctor}

Menos importantes para nosotros son Eutropio y Aurelio Víctor, ya que por las propias características de sus obras (breviarios o epítomes) se veían obligados a ofrecer información escueta, a menudo drásticamente resumida, que pudieron recopilar de otras fuentes, por desgracia perdidas para nosotros hoy. No obstante, ambos fueron burócratas de considerable cultura y educación que ocuparon puestos de gobierno a nivel imperial. Por ello los reseñaremos a continuación, ya que el devenir propio de estos autores ayudará mejor al lector a comprender ciertas características políticas y sociales del siglo IV. 
Sexto Aurelio Víctor (c. 320 - c. 390), desde un origen humilde y campestre, según él mismo nos cuenta, se convirtió, con estudio y trabajo, en un ilustre abogado, pese a que su padre era un pequeño campesino de la provincia de África. Ésta y otras variadas noticias acerca de su vida nos son conocidas gracias a su propia obra, el De Caesaribus o "Libro de los Césares", pues al contrario que la mayoría de sus contemporáneos, ofrece algunas informaciones autobiográficas. Pese a que se le puede enmarcar en la tradición de los autores de epítomes latinos del siglo IV, Aurelio Víctor tenía algo más de verdadero historiador, aunque el estilo tortuoso y moralizante, y su construcción oscura y recargada de arcaísmos, lo convirtieron en obra de difícil lectura.

Parece que tras comenzar una educación legal en su tierra se trasladó a Roma, donde ejerció como abogado, siendo a menudo testigo directo de los sucesos acaecidos allí. En 361 lo vemos, tras un afortunado encuentro con el recién proclamado Augusto Juliano, recibiendo el cargo de gobernador de Panonia Segunda, pues desde el primer momento su afición a la cultura, y seguramente también su paganismo, le hicieron ser bien considerado por Juliano, que le honró además con una estatua de bronce.

Con la muerte de Juliano parece que comenzó un periodo de mala suerte para Aurelio Víctor. En 363 o 364 cae en desgracia y pierde su puesto de gobernador. Pero su racha cambió y pudo vivir unos últimos años afortunados, al ser nombrado Prefecto de Roma por Teodosio I en el año 389. No conocemos con exactitud la fecha de su muerte, pero tuvo que acaecer poco después (Sancho Gómez, 2011).

Víctor escribió en latín, idioma oficial de la burocracia del Imperio, entre los años 359 y 361, y pese a las dificultades de su lenguaje, su epítome ha sido valorado positivamente en la actualidad por su disposición ordenada y la mezcla armoniosa de secciones biográficas ricas en datos con otras partes descriptivas, que lo han convertido en una pieza de estudio esencial para valorar la Roma del siglo IV. La obrita comenzaba con el reinado de Octavio Augusto y llegaba hasta los monarcas de su tiempo, Juliano y Constancio II (Bird, 1984; Sancho Gómez, 2009).

Eutropio fue el autor tardoantiguo más popular y conocido tanto en Occidente como en Bizancio durante la Edad Media, donde su Breviario se constituyó en referencia e incluso en libro de texto para el estudio de la historia romana, principalmente por su estilo claro y sencillo. La obrita narraba la historia desde la fundación de la ciudad con Rómulo hasta el reinado del emperador Joviano. Eutropio pudo ser oriundo de Italia o Asia, y se sospecha que, al igual que Amiano, era otro griego que escribió en latín. De familia acomodada, aunque no perteneciente a la nobleza (posiblemente de la clase media curial), se dedicó a labrarse una carrera dentro de la administración imperial, en la que medró y alcanzó notables éxitos. El único dato biográfico que conocemos sobre su persona es que participó, al igual que Amiano, en la campaña persa de 363 acompañando al emperador Juliano, quizá con el rango de magister epistularum.

Su famosa Breviarium historiae romanae fue publicada en 369, y en ella se aprecian las excelentes relaciones que mantenía por entonces, pues la dedicatoria agasaja al Augusto Valente en persona (364-378); Eutropio había alcanzado el cargo de magíster memoriae y la dignidad de vir clarissimi. Su prosperidad aumentó aún más, pues le vemos desempeñar el cargo de procónsul de Asia en 371. Pero a partir de entonces habrá problemas; envuelto en una trama oscura de magia, intrigas y traición, Eutropio caerá en desgracia. Este alejamiento, no obstante, no fue definitivo, y con el ascenso de Teodosio (379-395) le vemos recuperar el favor imperial, 
recibiendo la prefectura del pretorio por el llírico, que ostentó en 380-381. El cenit de su carrera llegaría al recibir el consulado de 387 junto al joven emperador Valentiniano II. En esos años, todavía recibirá una carta de su amigo Libanio, aunque se piensa que falleció poco después. Resulta sorprendente que su obra fuera traducida en una temprana edición griega en 380, algo insólito en la Edad Antigua, lo que puede dar una muestra del vivo interés que despertó desde su misma publicación (Bird, 1988).

\subsection{Juliano}

Juliano en sus obras también nos dejó una versión personal de los hechos que trataremos después, narración que por supuesto le es favorable. Flavio Claudio Juliano, tras su estadía de casi seis años en el Oeste (355-361), ofrece datos variados en su colección epistolar, desde las costumbres y el comportamiento de los "celtas" (nombre con el que la historiografía griega denominaba a los habitantes de la Galia) hasta las tradiciones germánicas que habían llegado a sus dominios, pasando por usos agrícolas, sucesos, anécdotas, descripciones físicas de interés, y algunas operaciones fluviales y terrestres, donde incluso podemos hallar la narración sucinta de algún episodio bélico, como el sitio de Sens en el invierno de 356, ciudad en la que quedó cercado sin apenas guardias o protección. Las cartas, especialmente las escritas en la Galia, nos ofrecen luz adicional en forma de comentarios en primera persona que ilustran la vivencia diaria y los aspectos más rutinarios de la vida del César en aquellas tierras. En sus panegíricos, además, contamos con una doble puesta en escena de la batalla de Mursa (año 351 ), imprescindible para comprender la historia del Imperio en el siglo IV; un testimonio julianeo que adquiere mayor importancia aún al no disponer del relato de los hechos escrito por Amiano Marcelino. De cualquier modo, cabe destacar que en todo momento Juliano se maneja con una soltura que demuestra sus reseñables dotes adquiridas como estudiante de filosofía; también debe tenerse en cuenta que la escasez de tiempo congénita a sus numerosas obligaciones como gobernante le privó muchas veces de la posibilidad de pulir y revisar su obra. No obstante, hace gala de un estilo y forma notables (Baker-Brian y Tougher, 2012; Sancho Gómez, 2011 ).

\subsection{Zósimo}

En última instancia está Zósimo, historiador denostado por la crítica contemporánea, que ofrece un relato de los hechos de nuestro interés con bastante detalle, aunque se trata del único testimonio muy posterior en el tiempo. Si bien es cierto que llama al emperador "Juliano el Grande" y que hace gala expresa de un paganismo militante a lo largo de toda su obra, que de hecho fue su motivación a la hora de escribir historia, nos resulta de utilidad en lo referente tanto a Magnencio como a Juliano.

Poco o nada conocemos del autor, que escribió su obra en un ámbito cronológico plenamente bizantino, se podría decir. Ostentaba el rasgo de comes y ejercía de abogado fiscal. Seguramente era originario de la ciudad de Constantinopla, o vivió en ella durante mucho tiempo, por las detalladas descripciones y los relatos de los sucesos acaecidos allí que nos ofrece. Su Nueva Historia, que se puede fechar razonablemente entre los años 498-527, plasma una sorprendente y demoledora cosmovisión pagana, que por primera vez se expresa en términos netamente religiosos para explicar la caída de Roma, la decadencia y el castigo divino, como colofón a una época de oscuridad y abandono del culto a los dioses: "Pues si Polibio narró cómo los romanos ganaron en poco tiempo su imperio, lo que yo me dispongo a contar es cómo en poco 
tiempo, y por su propia insensatez, lo perdieron" (Zos. I 57, 1). Exponer ideas contrarias al cristianismo en un momento tan delicado para los seguidores de la antigua religión hubiese sido difícilmente posible, por lo que se supone que se publicó tras la muerte de Zósimo. De cualquier modo, la sociedad bizantina de ese momento soportaba una legislación muy restrictiva contra los ciudadanos que no acatasen la ortodoxia, por lo que seguramente este autor, máxime cuando pertenecía al servicio imperial, siguió llevando su paganismo en secreto. Otro rasgo a destacar de su obra es que se cree que quedó inacabada, pues la narración finaliza de manera abrupta en 410 . Este autor, no obstante, por su propio interés, trata la época de Juliano minuciosamente. Con mucho, es también, de las fuentes empleadas, la más completa en lo referente a la rebelión y la monarquía de Magnencio, como ya se ha dicho (Sancho Gómez, 2011).

Zósimo ha pasado a la posteridad por sus juicios negativos y hostiles del emperador Constantino (306-337), incluyendo las cuestiones de organización estratégica, opiniones rechazadas casi siempre por la crítica reciente, pues como pagano, se argumenta, no podía ver al primer monarca cristiano sino con amargura y resentimiento. Pero ciertamente es el único que comenta los cambios realizados desde 308-312 en el ejército, y su opinión ha de ser tenida en cuenta. De hecho, se basa casi exclusivamente en premisas políticas y militares, siendo muy dependiente en todo momento de sus fuentes (Dexipo, Eunapio y Olimpiodoro), aunque ofrece ciertos añadidos personales, principalmente en forma de comentarios religiosos llenos de amarga ironía. Siempre se ha señalado, y con razón, el escaso valor literario de la Nueva Historia; el estilo de Zósimo es repetitivo, con ocasionales incongruencias, giros, desorden, interpolaciones, etc. La finalidad de esta obra ha sido también muy discutida, pero por su composición a caballo entre la historiografía clásica y las Historias Eclesiásticas, nos parece verosímil ver en su razón de ser una respuesta a estas últimas, utilizando su mismo estilo polémico para refutar y escarnecer las obras cristianas desde Eusebio de Cesarea hasta Orosio (Candau Morón, 1992; Goffart, 1971).

\section{Metodología}

Examinaremos ahora con detalle tres usurpaciones, las de Probo, Magnencio y Juliano, ya que, de modo excepcional, se nos han conservado en las fuentes literarias de forma algo más extensa, especialmente en el caso del controvertido emperador Juliano, ya marcadamente polémico entre sus contemporáneos, y cuyo recuerdo se ha mantenido a lo largo del tiempo de forma casi ininterrumpida. Pero no es nuestro interés ahondar en el estudio de factores y motivaciones, ya que tales temáticas han sido estudiadas de manera excelente para otros casos en años recientes, arrojando considerable luz y utilidad a la cuestión (Castillo Lozano y Molina Gómez, 2016). Por el contrario, nuestro enfoque comparativo intentará ceñirse al plano eminentemente técnico, por el que se desarrolla el fenómeno político-militar en sí.

\subsection{Objetivos y método empleado}

El objetivo de este trabajo es examinar, por medio de la comparación textual y el uso de bibliografía adicional, la información, enmarcada en su contexto histórico, procedente de las fuentes literarias, respecto al mecanismo (o mecanismos) por los que se fraguaba una conspiración política para cambiar el régimen desde el ejército, fenómeno habitual en el siglo Ill que devengó en una gran cantidad de las denominadas usurpaciones. Estos acontecimientos también están presentes durante el siglo IV, en el que no resultaron menos decisivos, pese a su inferior frecuencia. A continuación, pasaremos a analizar los tres casos recogidos en los autores anteriormente 
expuestos. Dada la naturaleza sucinta del relato, la referencia de Probo será la única citada íntegramente. Los otros testimonios, por su extensión, hacen imposible su reproducción total en este trabajo por obvios motivos de espacio.

Según Aróstegui (1995) la tercera fase del método histórico es la "Observación de las fuentes: crítica y análisis". Así, tras presentar las fuentes literarias de nuestro interés, procederemos ahora a la fase de crítica y análisis con atención al fenómeno estudiado, esto es, la faceta técnica de las usurpaciones. La hipótesis del actual trabajo radica en que es posible construir y exportar un modelo que explique, desde su faceta técnica, la trama y el desencadenamiento de las usurpaciones, a través del estudio de los autores recién mostrados y usando el método comparativo (Colino, 2009).

\subsection{El caso de Probo (junio de 276)}

El personaje aparece tradicionalmente en el cuarto lugar de la lista de los denominados "Emperadores Ilirios" (Cambi, 2017; Hiland y Oliva, 2013; Kreucher, 2003). El contexto histórico nos lleva al efímero mandato del emperador Tácito, cuyo interregno entre Aureliano y Probo, fabulado con profusión en una de nuestras tradiciones escritas, ocupa el fin del 275 y el principio del 276 (Syme, 1973). Anteriormente, tras el asesinato de Galieno, último emperador procedente de familias aristocráticas romanas, se habían sucedido los reinados de Claudio II (268-270) y Aureliano (270-275), que habían logrado revertir la caótica situación de modo notable, acabando con varias invasiones y secesiones. Probo continuará esta tendencia (Syvänne, 2020)2. El emperador Tácito fallece por fiebres, según versiones (Aur. Vic., 36, 1; Hist. Avg., Tac. 13,5), o asesinado, según otras (Zos. I 63, 2). Tal y como era su costumbre, ininterrumpida desde 268, el ejército se otorga la potestad de elegir un nuevo soberano (Potter, 2012; Wilkes, 1992, 262: "the Empire came under the control of the leading Illyriciani at Sirmium on Claudius' accession").

Nos encontramos frente al nuevo ejército romano que resurge de sus cenizas tras los graves estragos y debacles de la primera mitad del siglo III. Con una táctica más flexible, unidades muy móviles, nuevas formaciones de especialistas y dirigido por profesionales a tiempo completo, a menudo de raigambre campesina y oscuros linajes, pero curtidos por la experiencia y llegados con brillantez a lo más alto del escalafón, se iniciará una nueva etapa militar que acarreará la recuperación total y completa de las quebrantadas fronteras y la expulsión de los bárbaros germanos, sármatas y los persas, gracias al liderazgo y a la firmeza de las legiones y generales danubianos y balcánicos. Tales tropas, y sus cuadros dirigentes, se convertirán así en la verdadera esencia y en la razón de ser del "Nuevo Imperio" que empieza a vislumbrarse parcialmente con la llegada de Claudio II y alcanza su culminación en el reinado de Constantino (Ando, 2012; Richardot, 1998; Southern y Dixon, 1996; Syvänne, 2015).

Encontramos en la Historia Augusta lo siguiente:

Pero cuando discutían entre sí sobre quién debería ser elegido emperador y los tribunos les arengaban en el campo por escuadrones, diciéndoles que era preciso elegir como emperador a algún hombre valiente, recto, modesto, clemente y probo, y repetían esto por los múltiples corrillos que formaban los soldados, como suele acontecer, éstos a una, como por impulso divino, aclamaron por todas las partes:

\footnotetext{
2 Obviaremos a Quintilo, hermano de Claudio II, y a Floriano, familiar de Tácito, por su escasa significancia y por carecer de interés para nuestro presente trabajo.
} 
"Probo Augusto, que los dioses te protejan». Enseguida se reunieron junto a una tribuna de césped y le nombraron emperador ofreciéndole como adorno un manto de púrpura que quitaron a una estatua de un templo, y desde allí le condujeron de nuevo a Palacio, a pesar de que se oponía a ello, de que se negaba a avanzar y de que repetía, una y otra vez: "no os conviene soldados, no viviréis bien conmigo. Porque yo no puedo mostrarme blando con vosotrosll. Hist. Avg., Prob. 10, 4-53.

A continuación, pasaremos a desbrozar el citado pasaje. Los adornos retóricos resultan evidentes, así como el consabido tópico de la renuncia al poder, que aparece con profusión en las fuentes (Hdn. II 3, 3; D. C. LXXIX 12, 1; Zos. I 22, 1, etc.). Pero pese a ello, se pueden observar elementos dignos de consideración, si se toman por separado: en primer lugar, "discutían quién debería ser el emperador"; aunque la oración deja en suspenso el sujeto de esa acción, aludiendo sólo vagamente a "los militares", el caso mueve poderosamente a pensar en una camarilla organizada y aceptada, en la que se valoraban y elegían los posibles candidatos, una "junta", tal y como manifestó en su día Mocsy (1974, 210 y 216 ), seguido después por Tomlin (1987). Esto explicaría la larga sucesión de emperadores de raigambre balcánica, frecuentemente relacionados entre sí, desde 268 hasta 379, tal y como han reflejado Campbell (2002) y Scheidel (2013), aunque teóricamente el senado todavía "ratificaba" estos nombramientos.

Obviamente, el consenso en este tipo de situaciones sería necesario para minimizar la posibilidad de una batalla entre legiones, pues fenómenos de esa índole habían resultado desastrosos, al debilitar decisivamente las fuerzas del Imperio (Cromwell, 1998; Harries, 2012).

Pero quedaba la segunda parte de la tarea, de no escasa dificultad: convencer de modo eficiente a la amplia oficialidad intermedia y a la tropa rasa. Vemos en ocasiones a gobernantes plenamente consagrados por sus superiores, como Severo II durante la Tetrarquía, dejados de lado y abandonados por los soldados, lo que nos debe hacer considerar que las grandes decisiones de la "camarilla" ○ "junta" podían ser desoídas, por diversos motivos, aunque no sucediera de manera frecuente (Hanson, 1974; Shillam, 2007). La opinión de los legionarios y auxiliares debía ser tomada en consideración para aumentar al máximo las garantías de éxito.

Posteriormente aparece la intervención divina en la elección de Probo, en forma de uno de los portentos tan frecuentes en la obra, pero nos centraremos en el hecho de mayor relevancia para este trabajo: los tribunos militares arengan a las tropas, formadas en sus respectivas unidades (manipulos), y después, los soldados se juntan en corrillos, para sopesar o considerar las opciones: per multos círculos; ut fieri adsolet. Esto indicaría que el procedimiento resultaba frecuente en tales situaciones.

En definitiva, según este modelo, una serie de líderes de máximo rango, con amplios contactos, prestigio, autoridad e influencias, que tomarían las primeras decisiones, y las comunicarían de modo piramidal a la oficialidad, que sería a su vez encargada de arengar a los legionarios; estos, por último, puestos ante una o varias opciones, terminarían por aceptar a un candidato. Podemos considerar que en tales situaciones entrarían en juego una serie de factores para

\footnotetext{
${ }^{3}$ Sed cum inter milites sermo esset, quis fieri deberet, et manipulatim in campo tribuni eos adloquerentur dicentes requirendum esse principem aliquem fortem, sanctum, verecundum, clementem, probum idque per multos circulos, ut fieri adsolet, diceretur, quasi divino nutu undique ab omnibus adclamatum est: 'Probe Auguste, \{dii te $\}$ servent!' deinde concursus et $c<a>$ espiticium tribunal, appellatusque imperator, ornatus etiam pallio purpureo, quod de statua templi oblatum est, atque inde ad Palatium reductus, invitus et retractans et saepe dicens: 'non vobis expedit milites, non mecum bene agetis. ego enim vobis blandiri non possum.'
} 
facilitar, incitar o estimular a los soldados para que aceptasen el cambio de rumbo a través del quebrantamiento manifiesto de su juramento (sacrametum), insubordinación que de hecho estaba penada fuertemente y en caso de fracaso ofrecía múltiples peligros, entre ellos una más que posible ejecución, inmediata e ignominiosa (Perea Yébenes, 2017). Por lo tanto, los alicientes tuvieron que ser muy fuertes: donativos, botín, repartos posteriores del dinero o patrimonio de los rivales fenecidos, banquetes, y, por supuesto, vino. Estos dos últimos elementos como se verá, aparecerán claramente en los casos de Magnencio y Juliano.

\subsection{Magnencio en Aułun, 18 de febrero de 350}

Magnencio, un laetus por extracción, se había convertido en uno de los generales más importantes del ejercito romano, y con el rango de comes rei militaris estaba al mando de las legiones selectas loviani y Herculiani, la flor y nata de las tropas desde la Tetrarquía (Zos. II 42, 2). Al parecer, el emperador Constante había salido en una de sus cada vez más frecuentes partidas de caza; se le acusa de abandonar casi totalmente las tareas de gobierno en los últimos años para entregarse a las excursiones cinegéticas en compañía de su grupo de amigos (Zos. II 42, 2). Parece, en este sentido, que el descontento entre ciertos sectores del Imperio Occidental fue tomando solidez, y con el paso del tiempo, acabó extendiéndose hasta convertirse en una gran conjura. Tales ocasiones generaban evidentes situaciones para conspirar, pues el palacio imperial quedaba casi desierto de los principales apoyos del soberano y las altas personalidades opuestas podían reunirse y tramar, prácticamente a su antojo.

El conde Marcelino, aprovechando la ausencia del emperador, organiza una cena, con la excusa de celebrar el natalicio de su hijo, a la que naturalmente estaban invitados una importante cantidad de los altos mandos militares del ejército de Occidente. Pese a que tuvo que acompañarse de vino en copiosas cantidades, no puede admitirse ni el más mínimo atisbo de espontaneidad ante una escena largamente preparada, en la que todos los participantes estaban avisados de antemano; tan sólo quedaba esperar la señal convenida. Tras una leve interrupción, Magnencio se reincorpora a la velada cubierto de una clámide púrpura enjoyada y una diadema. Al instante, los presentes le saludan como Augusto (Zos. II 42, 3). El clamor se extiende por toda la ciudad (algo comprensible en estos casos, y que se repetirá posteriormente con el de Juliano), y los gritos hacen que las novedades se propaguen incluso por el campo, con lo que las gentes cercanas comienzan a afluir rápidamente. Muchas tropas del ejército galo hacen lo mismo; una vez conocida la noticia, hasta unidades de caballería estacionadas en el limes marcharán igualmente a la improvisada capital del usurpador, Augustodunum (actual Autun) para unirse a sus filas y saludarlo como emperador. En cuanto es informado de lo sucedido, Constante decide huir, pensando que en Hispania podrá ocultarse y/o escapar a los dominios de su hermano Constancio II, pero como se sabe, fue atrapado y asesinado antes de recibir socorro de sus partidarios (Eutr. X 9.4; Harries, 2012). Que el gobernante legítimo no intentase resistir, rehuyendo el enfrentamiento inmediato, es significativo. Probablemente recibió informes de sus fieles que dibujaban una situación catastrófica, ante la que sólo cabía escapar. A nuestro juicio, el hecho implica una concienzuda organización y planificación secretas, que llevarían operando un periodo considerable, necesario para lograr las ramificaciones y cohesión suficientes. Que ninguna de las unidades militares importantes del ejército en la provincia estuviera dispuesta a luchar por Constante parece clara conclusión del hecho de su intento de huida a Hispania (Harries, 2012). Estamos pues ante un plan orquestado posiblemente por una mente maestra; Juliano, en este sentido, acusará al ya mencionado comes rei privatae Marcelino de ser el "cerebro gris" de 
la usurpación, e instigador de muchos de los peores crímenes cometidos durante la usurpación de Magnencio (lul., Or. III 58-59; Sancho Gómez, 2011 ).

Cabe reseñar, en último lugar, que la ocasión seleccionada para realizar la escena final de la trama y dar comienzo a la rebelión fue un banquete nocturno. Esas situaciones parecen propicias, por diversos factores, para la materialización de proyectos sediciosos. La noche, con su oscuridad y tranquilidad, siempre ha sido momento elegido para todo tipo de alteraciones. Un banquete, además, presenta la excusa para ofrecer alcohol generalizadamente, enardecer los ánimos y proporcionar así el coraje para la decisión final a los timoratos e indecisos, ante acciones que ya no permitirían una marcha atrás. No fue ni la primera ni la última conjura que recibió la señal de salida en tales ambientes y circunstancias. Es más, entre las usurpaciones del siglo III, contamos con el relato de un caso parecido. Aunque debemos desbrozar y escrutar el pasaje, bajo sospecha por estar aderezado con los intempestivos y pueriles juegos de palabras tan del gusto de la Historia Augusta, apreciamos como en la narración de los "Treinta Tiranos", en el caso de Regiliano, o Regaliano, el complot aparece escenificado también en una cena de militares, que acaba con su proclamación como emperador; al contrario de lo que se da a entender, la escena no tuvo que tener nada de casual, al igual que con Magnencio (Hist. Avg., Tyr. Trig. 10, 3-7):

"En cierta ocasión en que Regaliano se hallaba cenando en compañía de algunos soldados, un lugarteniente del tribuno se levantó y dijo: "¿De dónde hemos de creer que proviene el nombre de Regaliano?" Inmediatamente otro afirmó: "Yo creo que viene de reino". Entonces uno de los que estaban presentes, que había sido estudiante, empezó a declinar como lo hacen los gramáticos, diciendo: «Rex, regis, regi, Regalianusı. [...] El día después de que tales frases fueran pronunciadas, cuando salió por la mañana, fue saludado como emperador por los soldados [...]. De este modo, lo que a otros les fue entregado mediante la audacia o una razonada elección, a éste se lo dio una aguda broma".

Era este Regaliano, al parecer, uno de los generales más importantes del llírico, provincia que se veía en situación crítica por las constantes acometidas e incursiones de pueblos bárbaros desde el año 258 , circunstancia que muy posiblemente propició su usurpación ${ }^{4}$.

\subsection{Juliano en Lutecia, febrero/marzo de 360}

Se trata del célebre "Juliano el Apóstata", cuya azarosa historia ha despertado el interés historiográfico y artístico continuamente, siendo prueba de ello la última monografía, aún reciente (Teitler, 2017), y un excelente Companion aparecido el pasado año (Wiemer y Rebenich, 2020). El caso de Juliano, dada la inherente controversia levantada por el protagonista desde el mismo momento de su muerte hasta la actualidad, fue tratado mucho más pormenorizadamente por los contemporáneos; así, conocemos con cierta seguridad su sublevación, lo que permite reconstruir moderadamente bien los hechos (Sanz Serrano, 2009). En las fuentes literarias antes descritas aparecen cuatro relatos favorables a Juliano, incluyendo el suyo propio, ya que a posteriori trató de ofrecer una explicación a lo acontecido en París. Los cuatro relatos (Amiano, Libanio, Zósimo, Juliano) ofrecen interesantísimas informaciones, que han dado pábulo a una extensa bibliografía

\footnotetext{
${ }^{4}$ Mirabile fortasse videatur, si, quae origo imperii eius fuerit, declaretur. Capitali enim ioco regna promeruit. Nam cum milites cum eo quidam c[a]enarent, extitit vicarius tribuni qui diceret: "Regiliani nomen unde credimus dictum?". Alius continuo: "Credimus quod a regno". Tum is qui aderat scolasticus, coepit quasi grammaticaliter declinare et dicere: "Rex regis regi Regilianus". Milites, ut est hominum genus pronum ad ea, quae cogitant: "Ergo potest rex esse?" Item alius: "Deus tibi regis nomen inposuit".
} 
moderna contraria a Juliano, en la que permanece la animadversión de los historiadores eclesiásticos contemporáneos al emperador, como Gregorio de Nacianzo (Así, Bowersock, 1978; Carrol Bark, 1978; Norwich, 2000; Ricciotti, 1959, entre otros). Pero pasemos al estudio de nuestro último caso de rebelión.

Juliano fue elevado al rango de César y enviado al norte por su primo el Augusto Constancio II con una pequeña escolta desde la capital imperial de Milán, en 355 (Aur. Vict., Caes. 42.17); poco más o menos, en esos momentos, recuérdese, empieza su correspondencia epistolar con Libanio. Existen trabajos valiosos que ofrecen una panorámica de la labor y/o reinado de Juliano como César en la Galia, en los que predominan las valoraciones positivas, aunque en ocasiones tintadas de tonos más oscuros o de sospechas hacia la fidelidad del personaje (Enjuto Sánchez, 2000). Contra lo que podría esperarse, dado que había recibido únicamente educación de carácter liberal y filosófica, el César se convirtió en un gobernante que fue cosechando éxitos militares y desarrollando una beneficiosa tutela sobre los provinciales, que le granjearon devoción y respeto en sus dominios. Debe recordarse que a la llegada de Juliano esas tierras estaban invadidas y recién saqueadas, afectadas por una gran multitud de problemas inherentes a la anterior guerra contra Magnencio. Juliano logró en algunos años que la situación mejorara sensiblemente.

El ambiente de optimismo reinante tras la expulsión de alamanes y francos, no obstante, iba a ser sustituido por nuevas preocupaciones: el commentariensis Decencio llegaría a la diócesis con un mensaje personal de Constancio II, a mediados de febrero o en marzo de 360, en el que el Augusto pedía refuerzos para su guerra contra los persas (Amm Marc. 20, 4, 2; Lib. Or. XVIII 91).

Constancio II estaba en su derecho de realizar tales peticiones, como señor supremo del Imperio que era, pero según parece, tales escritos estaban redactados de una manera desafortunada, con formas inadecuadas, ante una temática tan delicada y sensible, que muy pronto llenará a los galos de intranquilidad. Decencio, al parecer, actuó ignorando a Juliano, aspecto que debe añadirse a lo anteriormente mencionado. Lupicino, ausente realizando una misión militar en Britania, y Síntula, tribuno de los establos, eran los encargados de gestionar esa empresa, en la que el César ningún rol tenía, salvo dejar hacer (lul. ad Ath. 282c). Parece que el prefecto del pretorio Florencio estaba detrás de la idea, pues Amiano le acusa de promover en el ánimo de Constancio II el pedir a Juliano el grueso de sus tropas: las unidades más selectas al completo, y trescientos soldados de las restantes. Las tropas locales no querían abandonar esas tierras a su suerte, y muy probablemente se tuvieron que sentir irritados desde el principio. Quizá muchos de ellos estaban siendo obligados a separarse de sus familias. Además, verían con malos ojos un traslado lejano, a regiones de clima riguroso; esto era especialmente cierto para los alistados del otro lado del Rin, que tenían garantía expresa en sus acuerdos de no ser utilizados más allá de los Alpes (Amm. Marc. 20 4, 4; 20 4,7; 20 8, 16).

Realizados los preparativos para formar y organizar las unidades, Decencio se dispuso a partir hacia Italia; Juliano, según Amiano, le exhortaba a evitar áreas urbanas, pues sabía que en tales circunstancias los soldados serían propensos a causar problemas (Amm. Marc. 20 4, 11; también Lib. Or. XVIII 96; y lul. ad Ath. 283d-284a). El clima de indignación entre los legionarios galos y los auxiliares renanos, por no mencionar a la población civil, que contemplaba cómo estaba siendo privada de toda defensa, sirvió para fomentar, si no comenzar, la rebelión. Conforme las unidades estuvieron dispuestas, comenzaron a marchar hacia su nuevo destino; al pasar por la 
capital imperial en Lutecia (Lutetia Parisiorum, la actual Isla de Francia en París), el César salió a recibirlas a las afueras (Amm. Marc. 20 4, 3 y 5). Zósimo (III 9, 1) afirma que las tropas banquetearon alrededor del propio palacio de Juliano, y añade, de manera sorprendente, que los soldados galos aún no sabían que Constancio Il planeaba retirarlos de sus hogares, y que se enteraron esa noche gracias a escritos anónimos elaborados por los altos oficiales del ejército, libelos que son mencionados por el propio Juliano (lul. ad Ath. 283a-285d) y por Amiano (Amm. Marc. 20 4, 10). Ni Libanio (Or. XVIII 97) ni Amiano $(20$ 4, 12) mencionan la cena alrededor de palacio; lo más correcto y lógico es que las tropas hubiesen permanecido en las afueras, si bien los altos oficiales y portaestandartes pudieron en algún momento entrar en la ciudad y hacerse eco de la consternación de la población civil (Lib. Or. XVIII 96). En este ambiente de despedida, el mal ánimo de las tropas hubo de verse exacerbado por el vino y la cercanía de su anterior comandante, por el que sentían un conocido cariño (Zos. III 9, 2). Juliano trató de calmarlos con palabras afectuosas, y se retiró a sus aposentos, según parece, sin esperar ningún acontecimiento para aquella noche (Amm. Marc. 20 4, 11). Ningún testimonio menciona a los amigos del emperador, en el sentido del "círculo religioso/cultural/filosófico" en la trama.

Se debe recordar que el lugar de los hechos se veía afectado por una disposición geográfica particular; la única parte fortificada y amurallada de la ciudad era la isla en el Sena, en cuya ciudadela se hallaba el cuartel general de Juliano. El resto de la amplia ciudad romana de la época del Principado se encontraba en tierra firme y desprovista de defensa, pero tuvo que ser en esa parte donde se instalaron la mayoría de las legiones y las otras unidades del ejército, pues posiblemente no estaba previsto acomodar a una cantidad de hombres tan grande dentro de la fortaleza. Se necesitarían embarcaciones o el uso de los puentes para llegar al palacio desde los asentamientos/campamentos de los soldados, aunque las distancias no resultarían grandes, máxime sabiendo que, al tratarse de militares, contarían con el uso de caballos en gran número (de Carbonnières, 1997).

El siguiente hecho que viene a nuestro conocimiento es la cena que Juliano organizó para los oficiales; allí, de nuevo, según Amiano, trató de mostrarse comprensivo y amable con los que marchaban contra su voluntad. La crítica actual ha dictaminado casi unánimemente que en ella Juliano se dedicó a encrespar los ánimos de su estado mayor para que marchasen a encender a las tropas, provocando una rebelión; sabemos por los relatos coincidentes de todas las versiones que, a medianoche, las tropas, ahítas de comida y bebida, irrumpieron en la ciudad amurallada a gritos, rodeando el palacio, y que entonces Juliano lo hizo cerrar, permaneciendo hasta el alba enclaustrado y sin ver a sus soldados. Que los oficiales, exaltados después de hablar con su admirado César, corrieron por los campamentos repartiendo libelos y logrando así un amotinamiento masivo, es una conjetura que tiene sentido, si se contempla a la luz del fragmento en el que se describió la proclamación de Probo (Amm. Marc. 20 4, 14; Leedom, 1978; Lib. Or. XVIII 98-99). Zósimo (Zos. III 9, 2) afirma que los soldados forzaron las puertas de noche, invadiendo la residencia imperial desordenadamente, y sacando a Juliano a hombros. En el recién citado relato de Libanio se retrasa el forzamiento de las puertas palaciegas al amanecer.

Por la mañana, y tras consultar los signos divinos, Juliano sale al exterior para tratar de calmar a los soldados, sin éxito, y acepta finalmente ser proclamado Augusto. También ha de hacerse notar que las tropas, en estado de nerviosismo y preparadas para el combate, comenzaron a perder la paciencia, profiriendo insultos y amenazando con las armas. En ese clima tenso el César podría haber sido asesinado, algo ya ocurrido en numerosos casos de otros usurpadores efímeros 
que fueron proclamados y eliminados al poco tiempo, por no saber manejar la situación o satisfacer a sus encrespados seguidores, como el caso de Graciano en Britania (Oros. VII 40; año 406). Aceptar los requerimientos de las tropas, en segunda instancia, propició que volvieran a la calma, al ver su objetivo cumplido. Eso resultó clave a la hora de evitar que se produjeran represalias o excesos de carácter irreparable, en los alrededores o contra el funcionariado del gobierno imperial, blancos evidentes para los amotinados (Amm. Marc. 20 4, 21 ; Lib. Or. XVIII 98-100).

Al llegar la noticia de los sucesos acaecidos en París, las primeras tropas galas, que ya habían partido, dieron media vuelta, con Síntula a la cabeza, para integrarse de nuevo en el grueso del ejército (Amm. Marc. 20 5, 1). Esto nos hace pensar en una organización presta y eficaz, con mensajeros o exploradores que conocían bien los alrededores y comunicaron exitosamente los diferentes sectores de la rebelión, posiblemente al igual que en el caso de Magnencio.

\section{Resultados y Discusión}

Tras las comparaciones efectuadas mediante el estudio de las fuentes literarias, podemos destacar los puntos siguientes:

1. En primer lugar, existió siempre una camarilla ubicada en los altos escalafones del ejército romano, formada por militares profesionales de exitosa carrera, con ramificaciones y extensiones que alcanzaban probablemente la burocracia imperial, y que se encargó de idear y desarrollar los hechos narrados. No se puede admitir, en este sentido, que los "amigos filósofos" de, séquito de Juliano tuvieran peso y poder para urdir el complot de París en 360, logrando forjar una rebelión de miles de hombres armados. Como hemos dicho, no aparecen en los cuatro relatos principales del suceso. Así, contra las manifestaciones de Baldwin (1975), que se basa en un testimonio de Eunapio (Eun., VS, p. 149, Samaranch) debemos decantarnos por lo demostrado en Buck (1993). Esto no quita que el médico Oribasio se erigiese en una figura de absoluta importancia desde los primeros momentos para el devenir de Juliano.

2. La organización y las comunicaciones claras y veloces entre los distintos grupos conjuradores fueron esenciales, así como la fluidez, transversal y vertical, en el escalafón militar implicado. Queda claro en los casos de Magnencio y Juliano, y resulta plausible en el de Probo.

3. Pese a que una cúpula dirigente de pequeño tamaño debía tomar las decisiones, estas tenían que ser comunicadas a la tropa, que en ocasiones sumaba una cantidad muy importante de hombres. Tal proceso tuvo que ser el más largo y al mismo tiempo el más dificultoso. De no mediar una cuidadosa planificación, podría devengar muy bien en una pérdida de tiempo que hiciera fracasar los objetivos de la rebelión, o en un rechazo del candidato rebelde. No obstante, en los tres casos narrados se logra un éxito, definitivo o inicial, que parece indicar planificación y posiblemente mecanismos de control previo sobre la moral $u$ opiniones de la tropa rasa y la oficialidad intermedia, ya que, en ciertas circunstancias, como se ha dicho, ésta podía negarse a seguir formando parte de la rebelión y condicionar su fracaso, inmediato o no, mostrando tibieza u oposición directa.

4. Aunque desconocemos el caso de Probo, en las otras dos ocasiones los hechos suceden de noche, siendo ésta propicia para ese tipo de confabulaciones y golpes por sus evidentes ventajas. 
Pese a la carencia de información, es plausible que con Probo también aconteciera con nocturnidad la mayor parte del proceso, y que contase del mismo modo con la colaboración de medios de incitación para los soldados: premios, dinero, vino, banquetes, etc., que aparecen en las narraciones de Juliano y Magnencio y que facilitaban que la tropa pudiera tomar la decisión de rebelarse y dar un paso adelante llevado a cabo un acto de extraordinaria gravedad.

5. Los libelos son mencionados únicamente en el caso de Juliano, pero creemos que tuvieron que ser comunes, pues se trata de una herramienta recurrente y provechosa para comunicar ideas a la oficialidad y dar el empuje final a las situaciones previas de tensa calma, cuando las rebeliones están preparadas para estallar. Consideramos por tanto que, aunque no se mencionen, bien pudieron formar parte de las estrategias de complot en los casos de Magnencio y Probo, especialmente en el caso del primero, en el que aparece la figura previsora, experta y capacitada del conde Marcelino como urdidor y en el que existieron también condicionantes sociales y religiosos como parte de la conjura. Si bien es cierto que la mayoría de la población pudiera ser directamente analfabeta, la oficialidad intermedia ejercería como catalizador para la propagación rápida de mensajes claros, directos, y fáciles de memorizar. Si en el caso de París en 360 se emplearon libelos para difamar o denigrar a Constancio II, es muy probable que también aparecieran en otras situaciones similares.

6. Concluimos de este modo la investigación afirmando que el estudio comparativo de las fuentes literarias refrenda la hipótesis presentada en el trabajo, que alega la existencia de una vertiente técnica en el fenómeno de las usurpaciones, ya que cumpliendo ordenadamente una serie de pasos $\circ$ preparativos que aparecen, $\bigcirc$ son plausibles, en los tres casos estudiados, las confabulaciones contaban con mayores posibilidades de éxito. De tal modo, podríamos exportar el modelo creado a través del estudio de casos para ofrecer pautas que ayuden a reconstruir hechos históricos apenas reflejados en las fuentes, incluso en usurpaciones de las que desconocemos esencialmente su desarrollo.

Aunque es necesario seguir con la comparativa textual y los estudios de los grandes problemas que ofrecen los acontecimientos todavía escasamente tratados del siglo III, creemos haber hallado pautas para aumentar nuestro conocimiento acerca de los mecanismos que permitían llevar a cabo una usurpación, vistos desde el punto de vista técnico. Cabría, en trabajos subsiguientes, entroncar estas investigaciones con otros aspectos, como el económico, el militar y el social, para lograr así una perspectiva más clara y amplia de estos fenómenos, aún envueltos en numerosos interrogantes, pero sin duda de gran relevancia para el periodo histórico en cuestión.

\section{Reflexiones finales}

El mundo clásico grecorromano, basado en una red de ciudades con instituciones religiosas y políticas, vida civil y económica floreciente, y el denominado "patriotismo urbano" que vemos en la epigrafía, estaba todavía funcionando en grandes partes de la cuenca mediterránea a finales del siglo Il. Los sucesos que la historiografía tradicional ha enmarcado dentro de epígrafes como "Anarquía Militar" y "Crisis del siglo III" aceleraron a veces procesos ya latentes, y en otros casos propiciaron ex novo estructuras políticas y sociales diferentes. En ese periodo acontecieron fenómenos de amplísimas repercusiones que transformaron, en algunos casos radicalmente, el Imperio Romano. Las usurpaciones, sin poder explicar de por sí, obviamente, el vasto número de cambios políticos, sociales y económicos del momento, constituyen uno de los fenómenos más 
característicos de la época, por lo que su estudio, como en el caso presente, puede contribuir al conocimiento general del oscuro siglo III, plagado de cambios que se saben esenciales, aunque con frecuencia todavía desconocidos. Si contemplamos en el conjunto global las usurpaciones de los siglos III y IV, vemos que a menudo los escasos medios empleados o la débil situación estratégica y política de los sublevados ofrecían serios problemas, cuando no invitaban fuertemente al fracaso desde el comienzo. Que pese a ello las sublevaciones se llevasen a cabo en tan elevado número, debe hacernos pensar en profundas motivaciones, que muchas veces estaban mediatizadas por una inestabilidad crónica y situaciones de inseguridad, crisis y alarma generales, prolongadas a lo largo de varios años, y bajo la que subyacían, silenciosamente, las provincias más afectadas, cuyo sufrimiento, creemos nosotros, llevó tan a menudo a decidir soluciones desesperadas. En los tres casos del presente trabajo comprobamos, paradójicamente, que los conjurados lograron un éxito, al menos inicial: Probo, casi enseguida, obtuvo el reconocimiento de todo el Imperio, aunque después hubo de hacer frente a diversas usurpaciones y movimientos de resistencia (Aur. Vic., Caes. 37.3), para ser asesinado siete años después por los soldados (Aur. Vic. Caes. 37.4; Eutr. IX 17.2). Magnencio, pese a que llegó a controlar totalmente Galia, Hispania y Britania, sufrió un importante revés en la batalla de Mursa (actual Osijek, en Croacia). Tres años después de la usurpación, incapaz de de resistir y abandonado por muchos partidarios, puso fin a su vida. Su régimen, que había encontrado dificultades económicas desde el principio, osciló entre negociaciones diplomáticas y enfrentamiento abierto con Constancio II, de una manera que parece marcadamente incoherente. Juliano, por su parte, logró hacerse con la mitad occidental del Imperio de modo incruento, lo que resulta insólito, y posteriormente se vio beneficiado por la enfermedad de su primo, el Augusto Constancio II, que, seguramente deseoso de evitar más baños de sangre entre los ejércitos imperiales, nombró heredero en su lecho de muerte a Juliano, que era además el único miembro varón de la dinastía que seguía con vida. En ese momento, y dada su edad, Juliano podría haber desarrollado un largo y legal reinado en solitario, pero decidió embarcarse en la conocida invasión de Persia que acabó con su muerte en 363. En última instancia, los elementos más importantes para estos personajes, vilipendiados y a menudo desdichados en las fuentes literarias contemporáneas o posteriores, eran el arrojo y la rapidez, tras una buena organización previa y/o inicial. Sin descartar la ambición, a menudo el desencadénate de una usurpación se halló en la situación límite e insostenible que atravesaban ciertas regiones determinadas en un momento dado. Esas situaciones de dificultades y alarma existieron con mucha frecuencia en el siglo III, y también están presentes en el siglo IV. A propósito de todo ello, podría sacarse a colación, para finalizar, la sagaz opinión de Orosio (Oros. VII 40,6), testigo de frecuentes rebeliones, por la época en la que le tocó vivir y escribir: "Efectivamente, nadie hace una usurpación sino tras madurarla, por sorpresa, tras haberla llevado adelante en secreto, y defendiendo su posición después públicamente; y el éxito de esta acción consiste en que te vean con la diadema y la púrpura ya tomadas, antes de que sepan quién eres". Pero, de cualquier modo, la condición de tales individuos tendía a ser precaria en la mayoría de las ocasiones; como indicó en su día Adolf Schulten, "todo usurpador vive y muere con su suerte" (Schulten, 1949, 168).

\section{Agradecimientos y financiación}

Está trabajo no ha obtenido financiación en ningún concurso público. 


\section{Contribución específica de los autores}

El autor firmante del artículo es el único responsable del desarrollo de la investigación.

\section{Abreviaturas}

ACD. Acta classica Universitatis Scientiarum Debreceniensis. Debrecen: Debreceni Egyetem.

AClass. Acta classica: verhandelinge van die Klassieke Vereniging van Suid-Afrika $=$ proceedings of the Classical Association of South Africa. Pretoria: Classical Association of South Africa.

AHB. The Ancient History Bulletin = Revue d'histoire ancienne. Calgary (Alta.): University of Calgary, Department of Greek and Roman Studies.

AHR. The American Historical Review. Washington (D.C.): American Historical Association.

BRL. Bulletin of the John Rylands University Library of Manchester. Manchester: John Rylands University Library of Manchester.

Byzantion. Byzantion: revue internationale des études byzantines. Wetteren: Universa.

C\&C. Classica et Christiana. Center for Classical and Christian Studies, „Alexandru loan Cuza”. University of lasi, Romania.

Classica Cracoviensia. Classica Cracoviensia. Annual journal devoted to the studies of Greek and Roman Antiquity of the Institute of Classical Philology of the Jagiellonian University (Kraków, Poland).

CQ. Classical quarterly. Oxford: Oxford University Press.

EMC. Échos du monde classique = Classical views. Calgary (Alta.): University of Calgary Pr.

Florllib. Florentia lliberritana: revista de estudios de Antigüedad clásica. Granada: Ed. de la Universidad de Granada.

GRBS. Greek, Roman and Byzantine Studies. Durham (N.C.): Duke University, Department of Classics.

Hermathena. Hermathena: a Trinity College Dublin review. Dublin: University of Dublin, Trinity College.

Hermes. Hermes: Zeitschrift für klassische Philologie. Stuttgart: Steiner.

Historia. Historia: Zeitschrift für Alte Geschichte = revue d'histoire ancienne. Stuttgart: Steiner.

MHM. Miscellanea Hadriatica et Mediterranea, papers published by Department of History. University of Zadar, Croatia.

Philologus. Philologus: Zeitschrift für antike Literatur und ihre Rezeption. Berlin: Akademie Verl.

Polis. Polis: revista de ideas y formas políticas de la Antigüedad clásica. Alcalá de Henares: Universidad de Alcalá de Henares.

Potestas. Potestas, Religión, poder y monarquía. Revista del Grupo Europeo de Investigación Histórica. Universidad Jaime I, Castellón de la Plana, España. 
REIRE. Revista d'Innovació i Recerca en Educació. Publicació electrònica de la Secció de Recerca de I'Institut de Desenvolupament Professional (IDP-ICE) de la Universitat de Barcelona (Catalunya, Espanya).

Scientia et Technica. Scientia et Technica. Revista trimestral de la Universidad Tecnológica de Pereira (Colombia).

\section{Bibliografía}

Alföldy, G. (1974). The Crisis of the Third Century as seen by Contemporaries, Greek, Roman and Byzantine Studies, 15(1), 89-111.

Ando, C. (2012). Imperial Rome AD 193 to 284: the Critical Century. Edinburgh History of Ancient Rome. Edinburgh University Press.

Aróstegui, J. (1995). La Investigación Histórica: Teoría y Método. Editorial Crítica.

Bake-Brian, N. J., y Tougher, S. (Eds.). 2012. Emperor and Author: The Writings of Julian 'the Apostate'. The Classical Press of Wales.

Baldwin, B. (1975). The career of Oribasius. Acta Classica, 18, 85-97.

Bird, H. W. (1984). Sextus Aurelius Victor: A Historiographical Study. Francis Cairns.

Bird, H. W. (1988). Eutropius: his life and career. Échos du monde classique, 32(1), 51 -60.

Birley, A. R. (1976). The Third Century Crisis in the Roman Empire. Bulletin of the John Rylands Library, 58(2), 253-281.

Bowersock, G. W. (1978). Julian the Apostate. Duckworth.

Buck, D. F. (1993). Eunapius on Julian's acclamation as Augustus. The Ancient History Bulletin, 7, 73-80.

Cambi, N. (2017). Two Inscriptions Discovered in the Immediate Vicinity of Diocletian's Palace, Miscellanea Hadriatica et Mediterranea, 3(1), 139-156. Doi: https://doi.org/10.15291/misc.1355

Campbell, J. B. (2002). Warfare and Society in Imperial Rome, c. 31 BC-AD 280. Routledge.

Cardoso, C. (2000). Introducción al trabajo de la investigación histórica. Conocimiento, Método e Historia. Editorial Crítica.

Carrol Bark, W. (1978). Orígenes del Mundo Medieval. Editorial Eudeba.

Casey, J. (1995). Carausius and Allectus: The British Usurpers. B.T. Batsford.

Castillo Lozano, J. A., Molina Gómez, J. A. (2016). El castigo aplicado al "Tyrannus" Argimundo según el "Chronicon" de Juan de Bíclaro. Potestas, 9, 35-52.

Christol, M. (1997). L'Empire romain du IIle siècle. Histoire politique, 192-325 après J.-C. Errance.

Colino, C. (2009). Método comparativo. Diccionario Crítico de Ciencias Sociales. Terminología Científico-Social. Plaza y Valdés.

Cromwell, R. S. (1998). The Rise and Decline of the Late Roman Field Army. White Mane Publishing. 
De Carbonnières, P. (1997). Lutèce: Paris ville romaine, collection Découvertes Gallimard (no. 330), série Archéologie. Éditions Gallimard.

Dessau, H. (1889). Über Zeit und Persönlichkeit der "Scriptores Historiae Augustae". Hermes, 24, 337-392.

Enjuto Sánchez, B. (2000). La actuación del César Juliano en la Galia. Florentia Iliberritana, 11 , 55-68.

Enmann A. (1884). Eine verlorene Geschichte der römischen Kaiser und das Buch "De viris illustribus urbis Romae“. Philologus Suppl., 4(3), 337-501.

Fernández Ubiña, J. (1982). La Crisis del siglo IIl y el fin del Mundo Antiguo. Akal.

Goffart, W. (1971). Zosimus, the First Historian of Rome's Fall. The American Historical Review, $76(2), 412-441$.

Hanson, R. P. C. (1974). The Circumstances attending the Death of the Emperor Flavius Valerius Severus in 306 or 307, Hermathena, 118, 59-68.

Harries, J. (2012). Imperial Rome AD 284 to 363: The New Empire. Edinburgh University Press.

Hartmann, U. (2017). The Third-Century "Crisis". En M. Whitby, H. Sidebottom (eds.), the Encyclopedia of Ancient Battles, vol. III, Part VIII the Late Roman Empire (pp. 1047-1067). John Wiley \& Sons, Incorporated. Doi: https://doi.org/10.1002/9781119099000.wbabat0720

Hiland, S., Oliva, Ch. (2013). Le Règne de l'empereur Probus (276 - 282 apr. J.-C.) Histoire ef Numismatique. Editions III Monetae.

Leedom, J. W. (1978). Constantius II: Three Revisions. Byzantion, 48, 132-1 45.

López Eire, A. (1996). Semblanza de Libanio. Universidad Nacional Autónoma de México.

Kreucher, G. (2003). Der Kaiser Marcus Aurelius Probus und seine Zeit. Historia - Einzelschriften Band 174. Franz Steiner Verlag.

Matthews, J. F. (1989). The Roman Empire of Ammianus. Duckworth.

Mleczek, A. (2015). The counterfeit and fake emperor-Procopius in the Res Gestae of Ammianus Marcellinus. Classica Cracoviensia, 18, 255-291.

Mocsy, A. (1974). Pannonia and Upper Moesia. Routledge \& Kegan Paul.

Morgan, G. (2007). 69 A.D.: The Year of Four Emperors. Oxford University Press.

Norwich, J. J. (2000). Breve Historia de Bizancio. Cátedra.

Omissi, A. (2018). Emperors and Usurpers in the Later Roman Empire: Civil War, Panegyric, and the Construction of Legitimacy. Oxford University Press.

Perea Yébenes, S. (2017). Tronos ensangrentados (ca. 251-350). Quiebra del sacramentum militar y traición: de la securitas Augusti al crimen maiestatis. En: L. Montecchio (ed.), Tradimento e traditori nella Tarda Antichità (pp. 1-34). Edizioni Graphé.

Potter, D. S. (2004). The Roman Empire at Bay, AD 180-395. The Routledge History of the Ancient World. Routledge. 
Potter, D. S. (2012). Constantine the Emperor. Oxford University Press.

Ricciotti, G. (1959). Juliano, el emperador Apostata: según los documentos. Ediciones Eler.

Richardot, P. 1998. La fin de l'armée romaine: 284-476. Institut de Stratégie Comparée, EPHE IVSorbonne.

Sáez-Rosenkranz, I. (2016). El método histórico aplicado a la investigación educativa. Revista d'Innovació i Recerca en Educació, 9(2), 106-1 13.

Sancho Gómez, M. P. (2009). Actitud y pensamiento de Sexto Aurelio Víctor: algunos rasgos de un historiador en la roma tardía. Polis, 21, 37-57.

Sancho Gómez, M. P. (2011). Guerra y Política en el Imperio Romano de Occidente (337-361). Editorial Académica Española.

Sancho Gómez, M. P. (2016). Cato temporis sui: contemplando el senado romano tardío desde la Historia Augusta. Falsificación, literatura y pervivencias republicanas, Classica et Christiana, $11,247-274$.

Sancho Gómez, M. P. (2018). La religión del autor de la Historia Augusta. Monografías del CEPOAT (Centro de Estudios del Próximo Oriente y la Antigüedad Tardía).

Sanz Serrano, R. (2009). Fundamentos ideológicos y personales en el pronunciamiento del emperador Juliano. Potestas, 2, 83-11 15.

Schulten, A. (1949). Sertorio. Editorial Bosch.

Shillam, M. (2007). Abortive Dynasties: Dynastic Politics A.D. 235-285. Tesis doctoral, Universidad de Canberra.

Sidwell, B. (2008). Ammianus Marcellinus and the Anger of Julian. Iris, 21, 56-75.

Scheidel, W. (2013). The first fall of the Roman Empire. Annual lecture held in memory of eminent Roman historian Sir Ronald Syme. Oxford University Press.

Southern, P., Dixon, K. R. (1996). The Late Roman Army. Yale University Press.

Suárez, Montoya, O. (2008). De la téchne griega a la técnica occidental moderna. Scientia et Technica, 39(2), 298-303. DOI: https://doi.org/10.22517/23447214.3235

Syme, R. (1973). Danubian and Balkan emperors. Historia. 22(2), 310-316.

Syme, R. (1983). Historia Augusta Papers. The Clarendon Press.

Syvänne, I. (2015). Military History of Late Rome, 284-361. Pen and Sword Military.

Syvänne, I. (2020). Aurelian and Probus: The Soldier Emperors Who Saved Rome. Pen and Sword Military.

Tomlin, R. S. O. (1979). Ammianus Marcellinus 26.4. 5-6. The Classical Quarterly. 29(2), 470-478.

Tomlin, R. S. O. (1987). The Army of the Late Empire. En J. Wacher (ed.), the Roman World. Routledge Worlds (pp. 107-133). Routledge.

Teitler, H. C. (2017). The Last Pagan Emperor: Julian the Apostate and the War against Christianity. Oxford University Press. 
Velaza Frías, J. (2017). ¿El enigma imposible? Veinte años de estudios sobre la Historia Augusta. En J. de la Villa Polo, E. Falque Rey, J. F. González Castro, M. J. Muñoz Jiménez (eds.), Conventvs classicorvm. Temas y formas del Mundo Clásico. Vol. I (pp. 701-730). Sociedad Española de Estudios Clásicos.

Walser, G. (1965). The Crisis of the Third Century AD: A Re-Interpretation. The Bucknell Review, $13(2), 1-10$.

Wiemer, H-U., Rebenich, S. (2020). A Companion to Julian the Apostate. Brill's Companions to the Byzantine World. Brill.

Wilkes, J. (1992): The Illyrians. Blackwell Publishing.

Woods, D. (1998). Ammianus and Eucherius. Acta Classica Universitatis Scientiarum Debreceniensis, $41,105-117$.

\section{Fuentes}

Amiano Marcelino. Historia. Madrid: Akal. 2002. [Edición de $M^{a}$ Luisa Harto Trujillo].

Dión Casio. Historia romana. Madrid: Gredos. 2004. Biblioteca Clásica Gredos; 325, 326, 393, 395. [Traducción y notas de Juan Manuel Cortés Copete].

Eunapio de Sardes. Vida de filósofos y sofistas. Buenos Aires: Aguilar. 1975. [Introducción, traducción y notas por Francisco de Paula Samaranch Kirner]

Eutropio. Epítome. Aurelio Víctor. Libro de los Césares. Madrid: Gredos. 1999. Biblioteca Clásica Gredos; 261. [Introducciones, traducción y notas de Emma Falque Rey].

Herodiano. Historia del Imperio Romano después de Marco Aurelio. Madrid: Gredos. 1985. Biblioteca Clásica Gredos; 80. [Traducción, introducción y notas por Juan José Torres Esbarranch].

Historia Augusta. Madrid: Akal. 1989. [Edición de Vicente Picón García y Antonio Cascón Dorado].

Juliano, Emperador de Roma. Discursos. Madrid: Gredos. 1977. Biblioteca Clásica Gredos; 17. [Introducción, traducción y notas de José García Blanco].

Libanio. Discursos. Madrid: Gredos. 2001. Biblioteca Clásica Gredos; 290. III., Discursos julianeos. [Introducción traducción y notas de Ángel González Gálvez].

Orosio, Paulo. Historias contra los paganos. Madrid: Gredos. 1982. Biblioteca Clásica Gredos; 53, 54. [Introducción, traducción y notas de Eustaquio Sánchez Salor].

The Scriptores Historiae Augustae. Cambridge: Harvard University Press. 1968-1980 (3 vols.), (The Loeb Classical Library; 139, 140, 263). [With an English translation by David Magie].

Zósimo. Nueva historia. Madrid: Gredos. 1992. Biblioteca Clásica Gredos, 174. [Introducción, traducción y notas de José María Candau Morón]. 


\section{Panta Rei}

PANTA REI es una revista digital de investigación orientada a la Historia y otras ciencias afines. Su principal objetivo es la transmisión del conocimiento científico, dando una oportunidad también a los jóvenes investigadores que quieren abrirse camino en el estudio de las ciencias humanas y sociales. Se compone de estudios originales relacionados con la disciplina histórica así como su didáctica y difusión. Las diferentes secciones que componen la revista son: artículos de investigación, entrevistas a profesionales, recensiones de monografías de actualidad y crónicas de congresos o eventos científicos relevantes.

Todos los artículos publicados son objeto de un proceso de revisión a cargo de un mínimo de dos evaluadores, que se consideran expertos en el ámbito temático del artículo propuesto. Nuestro deseo es poder ofrecer unos contenidos rigurosos, de calidad y de interés.

El CEPOAT (Centro de Estudios del Próximo Oriente y la Antigüedad Tardía de la Universidad de Murcia) es la institución encargada de la coordinación y gestión de la revista, desde donde anualmente se lanzará la convocatoria para aquellos que estén interesados en publicar sus trabajos, siempre relacionados con la Historia, Arqueología, Historia del Arte, Didáctica de las Ciencias Sociales, etc.

PANTA REI is a digital journal focused on History and other sciences related to it. Its main objective is the transmission of scientific knowledge by giving also an opportunity to young researchers who want to make their way in the study of human and social sciences. It is composed by original studies related to History, as well as its didactics and promotion. The different sections of this journal are: research articles, interviews to professionals, recensions on monographs about current issues and reports about congresses or relevant scientific events.

All the articles published are subject to a revision process carried out by a minimum of two reviewers who are considered to be experts in the field of the article proposed. Our wish is to offer rigorous contents with quality and being of interest to the reader.

CEPOAT (Centre of Studies of the Middle East and Late Antiquity of the University of Murcia) is the institution in charge of the coordination and management of this journal. This is the centre from where the call for papers will be launched for all the people interested in publishing their papers, always related to History, Archeology, Art History, Didactics of the Social Sciences, etc. 


\section{Normas de publicación}

El autor se compromete a enviar trabajos originales, que no se encuentren publicados en otras revistas ni en otros idiomas. Así mismo, el mismo artículo no podrá ser presentado en otras revistas mientras dure el proceso de evaluación.

\section{Envío y presentación de originales}

Los artículos se enviarán exclusivamente a través del correo electrónico a la dirección pantarei@um.es. Los textos serán enviados en formato DOC y las imágenes en formato JPEG o TIFF, y con un tamaño mínimo de 2000 px. Éstas no aparecerán incorporadas en el texto, sino enviadas en archivo aparte y correctamente numeradas según su posición en el texto. Junto al trabajo, se rellenará y enviará un documento aparte en el que se especifiquen los datos del autor siguiendo el modelo disponible en la página Web de la revista.

Para la redacción de los trabajos se tendrá en cuenta el Manual de la American Psychological Association, en su sexta edición. La extensión máxima de los trabajos será de 30 páginas. La tipografía será Arial 11, con interlineado sencillo y sin espacio alguno entre párrafos. El texto deberá ir justificado a ambos márgenes y sin sangría en los primeros párrafos. Los márgenes serán de 2,50 cm. En los casos en los que fuera necesario incorporar notas, éstas irán a pie de página, enumeradas consecutivamente, con tipografía Arial 10, interlineado sencillo y justificadas a ambos márgenes.

Una información más detallada se encuentra disponible en la página http://www.um.es/cepoat/pantarei.

\section{Proceso de valoración y evaluación}

Una vez recibidos los trabajos, la Revista realizará una primera valoración. Si el trabajo enviado se ajusta a las normas de presentación propuestas, la temática es coincidente con la línea editorial de la revista y posee la calidad científica necesaria, será remitido al consejo asesor para una primera evaluación. Si no es así en este primer paso se puede rechazar directamente los documentos que incumplan claramente la línea editorial.

Será el Consejo Asesor quien indique a la revista la originalidad, relevancia, estructura, redacción, aparato bibliográfico, etc. del trabajo enviado y, para ello, se designará a dos revisores expertos externos que evaluarán cada uno de los trabajos, que pueden formar parte (o no) de este Consejo Asesor. La selección de los revisores se ajustará a la temática y características metodológicas del trabajo. El nombre y filiación de los autores serán eliminados del trabajo para su revisión, así como los revisores actuarán de manera anónima y confidencial.

Los revisores deberán rellenar un informe de evaluación que centrará su atención en aspectos tales como características formales, originalidad y novedad de los trabajos, relevancia de las propuestas y los resultados, calidad metodológica y validez científica.

Una vez terminado el proceso se decidirá la aceptación o no de los mismos y su publicación en el número que sea pertinente, así como las modificaciones susceptibles de ser realizadas para su final publicación. Dicha notificación se enviará únicamente por correo electrónico, en un plazo máximo de seis meses. 


\section{Publishing rules}

The author is committed to submit original papers not having been published in other reviews or in other languages. In this way, it is not allowed for the same paper to be presented in other reviews during the evaluation process.

\section{Submission and presentation of originals}

The articles will be exclusively submitted by email to pantarei@um.es. The texts will be submitted in DOC format and the images in JPEG or TIFF format, and with a minimum size of 2000 px. Images will not be integrated in the text but sent in another file and properly numbered according to their position in the text. Attached to the paper, a document will be filled out and sent where the author's data will be specified following the model available on the website.

The sixth edition of the Manual of the American Psychological Association will be taken into account for the writing of the papers. The length of the papers must not exceed 30 pages. Typography will be Arial 11, with simple line spacing and no space between paragraphs. The text must be justified on both margins without indentation in the first paragraphs. Margins size will be $2.50 \mathrm{~cm}$. Where it could be necessary the incorporation of notes, they will be at the bottom of the page, consecutively numbered with typography Arial 10, simple line spacing and justified on both margins.

More detailed information is available on the website: http://www.um.es/cepoat/pantarei.

\section{Examination and assessment process}

The Journal will submit the papers to a first examination once received. If the paper follows the presentation guidelines, the subject agrees with the editorial line of this journal, and possess the scientific quality required, it will be sent to the advisory council for a first assessment. If not, the documents which clearly fail to complete the editorial line may be rejected straightaway in this first step.

The Advisory Council will indicate the originality, relevance, structure, writing, bibliography, etc. of the text to the journal; for this purpose, two outside experts will be designated to review the papers; these experts can be (or not) part of this Advisory Council. The selection of the experts will adjust to the subject and methodological characteristics of the paper. Name and affiliation of the author will be eliminated from the text for its review, in this way experts will act anonymously and confidentially.

The experts will fill out an assessment report which will focus on aspects such as formal characteristics, originality and novelty of the papers, relevance and results of the proposal, methodological quality and scientific validity.

Once the process is finished, the acceptance or not of the papers and its publication in the corresponding edition will be decided, as well as the modifications that may be done for its final publication. This notification will be sent by email within 6 months maximum. 


\section{cepoAt edit.um}

